\title{
Addressing Teacher Shortages in the COVID-19 Landscape: Viewing Teacher Candidates as Assets
}

Excelsior: Leadership in

Teaching and Learning 2021, Vol. 13(2), 86-95

(C) The Author 2021

CC-BY 4.0 International Reprints and permissions: surface.syr.edu/excelsior https://doi.org/10.14305/in.19

440413.2021.13.2.01

nyacte.org

\section{Michael S. Rosenberg ${ }^{1}$, Loretta Mason-Williams ${ }^{2}$, Lois Kimmel ${ }^{3}$, and Paul T. Sindelar ${ }^{4}$}

\begin{abstract}
COVID-19 continues to impose dire consequences on all sectors of our public education system. Many students, particularly those from vulnerable populations, are receiving reduced amounts of direct instruction and are experiencing significant losses in learning. At the same time, educator preparation programs (EPPs) are struggling to ensure that teacher candidates have ample opportunities to apply their newly acquired pedagogical skills in high quality clinical placements. In this article, we describe and provide exemplars as to how teacher candidates can serve as assets to school districts as they complete their field placements. We also offer specific strategies and practices for EPPs and school districts to maximize the productive and efficient integration of teacher candidates in both virtual and in-person environments.
\end{abstract}

\section{Keywords}

educator preparation, field experiences, COVID-19, teacher shortages

\footnotetext{
${ }^{1}$ SUNY New Paltz

2 Binghamton University

${ }^{3}$ American Institutes for Research

${ }^{4}$ University of Florida
}

Corresponding Author:

Michael Rosenberg, School of Education, SUNY New Paltz, Old Main 114, New Paltz, NY, 12561

Email: rosenbem@newpaltz.edu

The conceptualization of this article was inspired by Mason-Williams, L., Rosenberg, M., Kimmel, L., \& Sindelar, P. (2020). Addressing shortages of educators in an uncertain COVID-19 landscape: viewing teacher candidates as assets. CEEDAR Center. https://ceedar.education.ufl.edu/wpcontent/uploads/2020/06/Addressing-Shortages-COVID-Landscape.pdf 
A former college basketball coach preparing to become a special education teacher in the Southern Tier of New York spent most of her Spring 2020 student teaching assignment on the bench, even as her mentor teacher struggled to deliver remote instruction to students with a range of learning and behavioral challenges. Well-prepared by a highly regarded state university and eager to assist, this talented career changer was frustrated knowing that the students and the cooperating mentor teacher needed knowledgeable assistance. Rather than stepping in to assist individual students or develop accessible online materials, she was sidelined by both the pandemic and district policies that prevented her from helping families or her mentor teacher and limited her chances to develop the skills she needed for her own professional growth.

In sharp comparison, another student teacher in New York's Hudson Valley had far more responsibility for the students in her placement. She delivered remote small group science, social studies, and language arts instruction. Working collaboratively with her mentor teacher, this teacher candidate had a well-supervised, clinically rich experience that allowed students to acquire new content, review skills, and have opportunities for supervised practice. The student teacher was well-versed in digital technology, so this collaboration also served to ease some of the stress for the mentor teacher who was responsible for a quick pivot to on-line instruction.

The uncertainty and challenging times wrought by the global pandemic has enormous consequences for student learning, teachers, and teacher preparation. In this paper, we offer a framework to assist EPPs and districts to reframe partnership activities that would allow teacher candidates to serve as assets in schools and examine how such arrangements can help address challenges created or exacerbated by COVID-19, such as longstanding gaps in student academic achievement and the special education teacher supply.

\section{Challenges Created or Exacerbated by COVID-19}

The COVID-19 crisis is imposing dire consequences for all sectors of our public education system. Even with the noble efforts of teachers, administrators, and family members to provide remote instruction, many students are experiencing significant losses in learning (Kuhfeld et al., 2020). The learning loss is inequitably distributed with the greatest disparities occurring among already vulnerable populations of low-income students and students of color, exacerbating existing achievement gaps (Dorn et al., 2020; Story \& Slavin, 2020). Unfortunately, these troubling problems are likely only the tip of the iceberg. The COVID-19 crisis is not just a short-term threat (Sharfstein \& Morphew, 2020); the effects of the crisis will have lasting impact on student academic achievement and social-emotional development, and influence how we have traditionally measured and accounted for student outcomes. Teacher preparation efforts are also in flux and vigilance will be required in assessing the impact of our hasty, albeit well-intentioned, curricular adaptations.

At the same time, COVID-19 will likely have a considerable impact on the special education teaching supply. Historically, supplying all schools and classrooms with fully prepared, qualified special education teachers has been a considerable challenge. Ample evidence suggests critical shortages, especially in schools serving students from low-income areas, schools primarily serving students of color, and in rural schools (Croc \& Yang, 2016; Mason-Williams, 2015; Sindelar et al., 2018). Moreover, preparation appears to matter for retention and avoiding burnout, indicating how essential it may be to maintain clinical practice activities so novice special educators feel adequately prepared for 
their role (Billingsley \& Bettini, 2019; Ondrasek et al., 2020). Teacher candidates' completing programs with abbreviated field experiences may not feel as prepared, making them more vulnerable to attrition or feelings of inadequacy.

\section{Viewing Teacher Candidates as Assets}

Cutting short the field experiences of teacher candidates may also overlook the considerable resource they can be in classrooms, especially in under-resourced schools. Early estimates clearly indicate that students made vulnerable by poverty or other factors (e.g., disability, English language learners, lack of internet access or access to technology) will experience the greatest losses in academic achievement, but that tutoring programs can effectively help to overcome such losses (Nickow et al., 2020). Providing opportunities for teacher candidates, who are arguably better prepared to serve as tutors than individuals from other majors, can help to ameliorate some of the learning loss by either directly assisting the learners or by supporting classroom teachers, thereby allowing the teachers to better support the learners.

As school district leaders and policy makers in New York State and across the nation consider various scenarios to educate students in an uncertain COVID-19 landscape, they are facing reduced budgets, uncertainties about instructional delivery, and challenges surrounding the safety and wellbeing of students and educators. Such uncertainties may deprioritize collaborations with local educator preparation programs (EPPs. Although urged by some state education agencies (e.g., New York State Education Department [NYSED], 2020) to work with EPPs to identify ways student teachers can support classroom instruction, school districts-like the district in the Southern Tier described earliermay shy away from welcoming preservice teacher candidates. Facing time-consuming security and privacy policies and not knowing how best to integrate a developing teacher into an uncertain instructional landscape, some districts may simply avoid what they perceive as an added burden on their overtaxed teachers and overwhelmed administrators.

That said, many school districts and EPPs have a strong and productive history of working together in the initial preparation and ongoing professional learning of teachers and leaders. These relationships, such as the partnership established in the Hudson Valley, allow for creative problem-solving and the leveraging of resources and expertise, achieving outcomes that would not be realized without cooperative involvement (Rosenberg et al., 2009). Productive EPPs work with school districts to gradually integrate clinical experiences throughout teacher preparation programs, initially though observational and data-collection activities that augment course content material, and then in instructional situations under the tutelage of mentors (TeachNY, 2016). Teacher candidates do not need to wait for their culminating student teaching experience to begin applying newly acquired pedagogical skills; microteaching activities in increasing complex and challenging situations, accompanied with supervisory support and directed feedback can boost teacher candidate performance and their sense of self-efficacy (Arsal, 2014).

We advocate that school district personnel view teacher candidates as assets. With appropriately structured EPP supervision, well-prepared teacher candidates can augment veteran teachers' efforts while successfully honing their own professional practices and fulfilling licensure requirements. Moreover, teacher candidates may help address teacher shortages that may occur due to efforts to reduce classroom and school building density. Instead of forgoing or delaying partnerships, districts, in concert with EPPs, have an opportunity to reimagine and innovate how field experiences are best 
organized and delivered. Similarly, state departments of education (SEAs) must be prepared to make accommodations and provide support for teacher candidates and EPPs who may not be able to complete fieldwork in a traditional fashion. Changes to common practices and policies may be necessary to allow maximum flexibility for teacher candidates to demonstrate skills, either in person or virtually, and progress toward graduation and licensure.

In the following sections, we describe ways teacher candidates can serve as assets to school districts, offering specific strategies and practices for EPPs to maximize the productive and efficient integration of their teacher candidates. As Table 1 demonstrates, these suggestions often require active and cooperative participation from both districts and EPPs. Because teacher candidates usually engage in increasing levels of instructional responsibilities during their preparation programs, we align the strategies to the three typical levels of clinical practice recommended by the NYSED Clinical Practice Work Group (2018). During the first stage candidates gain Early Foundational Skills through limited engagement in classroom settings, often coupled with introductory coursework in child development and disability. Fieldwork expectations range in scope, but typically include spending time observing classroom instruction or interviewing practitioners. At the next stage, candidates typically engage in Intermediate Practice, spending more time as active participants within a classroom. At this time, their preparation shifts to courses focused on instructional and pedagogical methods and is typically accompanied by lengthier engagement in classroom settings with expectations for providing some instruction and assisting learners. At the end of preparation, candidates typically complete Culminating Experiences, characterized by full-time engagement in a classroom setting as a student teacher, intern, or resident. These stages provide a useful framework for considering how fieldwork may be reconceptualized, potentially increasing their utility, as EPPs and district administrators continue to adjust instructional delivery during the pandemic and beyond.

\section{Foundational Skills: Observing, Creating, and Assisting}

At the early stages of their preparation programs, teacher candidates are beginning to explore and reflect upon elements of evidenced-based instructional practices, the social and emotional development of learners, and the multiple roles and responsibilities of classroom teachers. In coursework, beginning teacher candidates learn about curriculum, engage in opportunities to experience planning for instruction, and discuss typical and atypical child and adolescent development. Although not always ready to provide instruction, teacher candidates' eagerness to help and willingness to apply newfound skills can, for example, help mitigate the challenges of teachers trying to monitor two classrooms simultaneously: one in person and one via remote learning. Specifically, in configurations where at least a portion of instruction is provided online, new teacher candidates can (a) monitor small groups, either in person or in virtual breakout rooms; (b) develop short, content-focused videos on essential topics for review and fill gaps during times spent in online instruction; (c) assist with locating and vetting online instructional materials (e.g., videos, worksheets, and other materials); (d) create support materials, such as scaffolded notes and graphic organizers; (e) contribute in making materials more accessible by helping with closed captioning, narrating slide presentations, and reading text aloud; and (f) post materials to online sites, such as Schoology, Google Classrooms, Blackboard, or other learning management system (LMS) apps. Access to technologies such as Pear Deck (an add-on feature for Google Slides or PowerPoint) and other interactive technologies allow teacher candidates to make connections with learners and help support social-emotional learning. Ultimately, such activities can help the classroom 
teacher by freeing up time to work directly with students in the classroom or provide feedback virtually.

Table 1

Teacher Candidates as Assets: Opportunities and Considerations for In-Person and Remote Instruction Possibilities

\begin{tabular}{|c|c|c|}
\hline & Opportunities in Schools & EPPs Should Consider \\
\hline $\begin{array}{l}\text { Foundational } \\
\text { Skills }\end{array}$ & $\begin{array}{l}\text { - Develop content-focused videos } \\
\text { - Assist with locating and vetting online } \\
\text { materials } \\
\text { - Create support materials (scaffolded } \\
\text { notes, graphic organizers) } \\
\text { - Monitor small groups (in person \& } \\
\text { online) } \\
\text { - Post materials to LMS }\end{array}$ & $\begin{array}{l}\text { - Require modules on accessibility } \\
\text { features } \\
\text { - Share ways to evaluate materials } \\
\text { - Evaluate candidate tech expertise } \\
\text { - Teach about online security, } \\
\text { confidentiality, \& privacy } \\
\text { - Require mandated reporting } \\
\text { requirements earlier }\end{array}$ \\
\hline $\begin{array}{l}\text { Intermediate } \\
\text { Practice }\end{array}$ & $\begin{array}{l}\text { - Teach small groups } \\
\text { - Targeted? } \\
\text { - Assess gaps? } \\
\text { - Reteach/remedial? } \\
\text { - Create review \& extension activities } \\
\text { - Provide feedback \& oversee online } \\
\text { activities } \\
\text { - Screening/benchmarking }\end{array}$ & $\begin{array}{l}\text { - Allow "hours" to be met online OR in- } \\
\text { person } \\
\text { - Assign candidates to a building/team } \\
\text { - Collaborate with districts to meet } \\
\text { pressing needs } \\
\text { - Do supervision remotely }\end{array}$ \\
\hline $\begin{array}{l}\text { Culminating } \\
\text { Experiences }\end{array}$ & $\begin{array}{l}\text { - Allow candidates to take full } \\
\text { responsibility- in person AND online } \\
\text { - Assign strong student teachers to CTs } \\
\text { with health concerns } \\
\text { - Encourage team and co-teaching } \\
\text { - Pair strategically to balance strengths } \\
\text { (and needs) }\end{array}$ & $\begin{array}{l}\text { - Discuss what contact with families } \\
\text { might look like and implicit bias } \\
\text { - Promote virtual platforms for } \\
\text { mentoring } \\
\text { - Reconsider evaluation systems } \\
\text { - Allow student teachers to } \\
\text { demonstrate skills in unconventional } \\
\text { ways }\end{array}$ \\
\hline
\end{tabular}

To ensure candidates are prepared for this challenge, EPPs may want to quickly provide candidates with opportunities to plan and prepare materials for online and in person instruction, as well as to protect the safety and security of students, manage disclosures, and set boundaries, both in person and online. Prior to entering their clinical experience, teacher candidates should complete training on instructional technology accessibility, receive guidance on how to locate district curricular resources and reputable online materials, and have an awareness of how to evaluate instructional materials for curricular alignment, appropriateness, and accuracy. The safety, security, and privacy of students are also critical, and teacher candidates will need to complete mandated training and reporting requirements (e.g., fingerprinting, on-line safety modules such as those offered by Common Sense Media or from the Office of Justice Programs) as well as maintain confidentiality of student records.

Unfortunately, in 2020 many EPPs and districts were reluctant to integrate teacher candidates into field experiences at this foundational stage. Rather, informal discussions with several EPP faculty and 
staff indicated frequent integration of video analysis into courses, taking advantage of resources like the Atlas library from the National Board for Professional Teaching Standards or the Teaching and Learning Exploratory site hosted by the University of Michigan. At one EPP, however, it was reported that teacher candidates had the benefit of continued participation in the well-established Liberty Partnership Program (LPP). In this program, LPP coordinators place volunteers from a wide-range of university majors, including teaching candidates, in half-day placements at qualifying, high-needs partner schools. During the placement, LPP volunteers provide tutoring in academic content areas to students identified as vulnerable or at risk for school failure. Anecdotal reports indicated that these experiences allowed teacher candidates opportunities to develop relationships with students, leading to several long-term commitments to assist at the schools, including during semester breaks.

\section{Intermediate Practice: Gaining Experience}

Teacher candidates at this intermediate stage of development are ready to teach small groups of learners, especially those who are experiencing difficulties and require additional instructional support. School districts can leverage the developing expertise of teacher candidates to help fill learning gaps and aid those who need it most. Specifically, teacher candidates can (a) create and present remedial or practice activities for individual and small groups of students; (b) provide feedback on work submitted virtually, such as short answer responses and "leveling up" on websites that help differentiate, support, or extend student independent learning, such as Zearn or Reading A to Z; (c) assist with screening and benchmarking activities, including reflecting on collected data to identify learning gaps and targeted plans for intervention; and (d) continue assisting with making materials accessible, posting materials to an LMS, and finding extension activities (for both in person and online learning).

To facilitate the integration of teacher candidates at this stage, changes in policies regarding how placements and assignments are assigned, configured, supervised, and evaluated may be necessary. Assuming a considerable number of students will spend time both in school and in remote hybrid learning environments, EPPs will need to allow field-based assignments to be completed through both platforms (with monitoring provided by a cooperating teacher). District logistical plans may also dictate that teacher candidates be assigned to grade-level teams or school buildings rather than to a single teacher, allowing their time to be used flexibly to assist target students. Correspondingly, teacher candidate support, feedback, and performance evaluation feedback will need to accommodate remote learning and be completed through virtual platforms if in-person options are not possible. Finally, EPPs can assist district partners by assigning technology-savvy teacher candidates with veteran teachers who may be struggling with myriad virtual learning operations, easing their stress and enhancing pedagogical skills. To help facilitate such opportunities, districts may need to provide teacher candidates with access to and training in local platforms.

Unfortunately, the extended time and increased responsibilities expected during the Intermediate Stagemade it difficult for many EPPs in 2020 to secure appropriate placements. As with Foundational Skills programming, experimental and innovative uses of video and virtual reality took the place of direct contact with students. However, one EPP partnered with the local BOCES to allow teacher candidates to attend professional learning opportunities prior to the start of the semester. As the faculty members and district partners recognized that the teacher candidates would assist with both in-person and remote instruction, teacher candidates were encouraged to attend workshops on many of the instructional learning platforms used by classroom teachers. EPP personnel reported anecdotally that 
the preparation allowed teacher candidates to be prepared to assist in multiple ways, even seamlessly taking on long-term substitute teacher roles when classroom teachers needed to quarantine.

\section{Culminating Experiences: Teacher Candidate to Novice Teacher}

Teacher candidates entering the student teaching phase need opportunities to learn from experienced teachers as well as opportunities to demonstrate their independence. Simultaneously, concerns regarding the health of veteran teachers who may be unable or unwilling to return to classrooms may leave school districts scrambling to fill positions or to identify creative personnel solutions. In fact, this may lead to innovative opportunities for collaboration, as capable teacher candidates can assume the role of in-school instruction provider, with remote technology-based assistance from mentor teachers. Mentor teachers would still be considered teachers of record, but responsibilities would focus on planning, providing instruction in remote settings, and providing virtual mentorship. School districts may want to consider this and other novel ways to reimagine the roles and responsibilities of wellprepared student teachers. Regardless, school districts can encourage opportunities to implement team teaching and coteaching approaches, thereby enabling student teachers to have naturally supported opportunities for planning, delivering, and evaluating instruction. Finally, capable student teachers can assume full responsibility for the remote learning for one or more groups of students and could be purposefully assigned to cooperating teachers with health concerns. If necessary, teacher candidates could even serve as a temporary long-term substitute teacher maintaining continuity in classroom climate, instruction, and communication with families and related service providers.

To promote any of these opportunities, EPPs may need to make allowances to existing policies. For instance, longstanding decisions to not allow teacher candidates to substitute teach may need to be reconsidered and emerging supportive technologies may need to be adopted. Consequently, EPPs will benefit from working closely with local districts to target the placement of student teachers to schools in most need of assistance. Moreover, allowing student teachers to demonstrate skills in unconventional ways, such as through collaborating with multiple teachers across multiple classrooms, may require EPPs to evaluate the utility of existing teacher evaluation rubrics, recognizing that some rating systems may not be flexible enough or include opportunities to provide feedback on the new roles. Finally, since student teachers may assume more prominent roles in the classroom ecology, they will likely require explicit guidance regarding the consulting services of fellow professionals, methods of collaborative consultation, and appropriate contact with families during in-person and remote interactions (Rosenberg et al., 2006). While some of these changes to the student teaching semester may make it difficult to maintain integrity to "typical" or traditional practices, the added benefit to learners, especially those vulnerable to learning loss, and the added experience gained by teacher candidates may far outweigh the challenges.

At one EPP, comments shared anecdotally by cooperating teachers underscore the benefit to finding ways to maintain student teaching partnerships. Perhaps most noted is the gratitude expressed for having student teachers available to assist with technology in Spring and Fall of 2020. While not all teacher candidates are technology experts, just the added pair of hands and eyes to monitor chat boxes and breakout rooms or to try to learn something new could be beneficial and increase opportunities for engagement and learning among students. 


\section{Conclusion: Moving Forward}

Field experiences are among the most important components in the pre-service professional development of effective teachers. They provide a vital link between the knowledge base presented in classes to the activities expected of practicing teachers. Under ideal conditions, developing teachers, like the technology savvy student teacher from the Hudson Valley, are (a) placed in real world situations that allow for the identification of strengths and weaknesses; (b) provided structured and increasingly complex opportunities to enhance creatively areas of strength and improve assessed deficiencies; and (c) given opportunities to experience the daily contributions, rewards, and challenges inherent in teaching (Rosenberg et al., 2006; TeachNY, 2016).

The impacts of COVID-19 on education and teacher preparation are undeniable, impacting colleges and their EPPs in terms of learning, place, equity, enrollment, and budget (Dorn et al., 2020). Specifically, the pandemic is upending EPP's explicit instruction of evidence-based practices, forcing radical changes in the provision of clinical experiences, and altering the shared in-person experiences of preservice teachers, faculty, students, families, colleagues, and mentors. How EPPs will deliver on their teacher preparation missions remains uncertain as does the efficacy of altered requirements and policies. Similarly, shifts in expectations and roles throughout preparation in response to COVID-19 may require districts and EPP partners to reevaluate long-held policies and practices regarding access to technology and adequate bandwidth for vulnerable students, such as those with disabilities and those who reside in under-resourced communities and attend high needs schools. Finding opportunities for teacher candidates, and perhaps the university faculty members who work with them, to participate in professional learning opportunities surrounding the technology, may prove crucial in supporting classroom teachers. Moreover, it can assist with a more seamless transition from candidate to novice teacher. In short, sidelining enthusiastic, well-prepared student teachers like the college basketball coach from the Southern Tier makes little sense in times of great need.

Disruptive events can be the true drivers of change in higher education (Zemsky, 2013). If there is any silver lining to the current disruptions associated with COVID -19 and its corresponding impact on clinical experiences, it is that opportunities for innovation and growth are possible during challenging times. Looking back, we may come to realize the positive impacts the crisis has had on instruction, including gathering resources that allow teachers to extend student content knowledge, providing new ways for students to demonstrate their understanding, and offering exciting opportunities for peers to collaborate. Focusing on teacher candidates as assets may help EPPs and school district partners recognize these possibilities.

\section{Declaration of Conflicting Interests}

The author declared no potential conflicts of interest with respect to the research, authorship, and/or publication of this article.

\section{Funding}

The authors received no financial support for this research. 


\section{References}

Arsal, Z. (2014). Microteaching and pre-Service teachers' sense of self-efficacy in teaching. European Journal of Teacher Education, 37(4),453-464. https://doi.org/10.1080/02619768.2014.912627

Billingsley, B., \& Bettini, E. (2019). Special education teacher attrition and retention: A review of the literature. Review of Educational Research, 89(5), 697-744. https://doi.org/10.3102/0034654319862495

Croc, N., \& Yang, M. (2016). Diversity and equity in the distribution of teachers with special education credentials: Trends from California. AERA Open, 2(4), 1-15. https://doi.org/10.1177/2332858416679374

Cuenca, A., \& Zaker, J. (2019). The use and utility of video representations in early social studies field experiences. Contemporary Issues in Technology and Teacher Education, 19(4), 770-789. http://www.learntechlib.org/p/207290/

Dorn, E., Hancock, B., Sarakatsannis, J., \& Viruleg, E. (2020). COVID-19 and student learning in the United States: The hurt could last a lifetime. https://www.mckinsey.com/industries/publicand-social-sector/our-insights/covid-19and-student-learning-in-the-united-states-the-hurtcould-last-a-lifetime

Kuhfeld, M., Soland, B. Tarasawa, A., Johnson, Ruzek, E, Liu, J. (2020). Projecting the potential impacts of COVID-19 school closures on academic achievement. Educational Researcher, 49(8), 549-565. https://doi.org/10.3102/0013189X20965918

New York State Education Department (2018, January). Clinical practice workgroup. New York State Education Department. http://www.nysed.gov/clinical-practice-work-group/clinicalpracticework-group

New York State Education Department (2020, July). Recovering, rebuilding, and renewing: The spirit of New York's Schools reopening guidance. New York State Education Department. http://www.nysed.gov/news/2020/state-education-department-presentsframeworkguidance-reopen-new-york-state-schools

Nickow, A., Oreopoulos, P., \& Quan, V. (2020). The impressive effects of tutoring on pre $K$-12 learning: A systematic review and meta-analysis of the experimental evidence. National Bureau of Economic Research Working Paper Series. https://doi.org/10.3386/w27476

Ondrasek, N., Carver-Thomas, D., Scott, C., \& Darling-Hammond, L. (2020). California's special education teacher shortage. Learning Policy Institute. https://edpolicyinca.org/sites/default/files/2020-02/r ondrasek feb20.pdf

Rosenberg, M., Brownell, M., McCray, E., deBettencourt, L., Leko, M., \& Long, S. (2009). Development and sustainability of school-university partnerships in special education teacher preparation: A critical review of the literature. (NCIPP Doc. No. RS3). University of Florida, National Center to Inform Policy and Practice in Special Education Professional Development. Retrieved from: http://ncipp.org/reports/rs 3.pdf

Rosenberg, M., O'Shea, L., \& O'Shea, D. J. (2006). Student teacher to master teacher (4th ed.). Merrill/Prentice Hall.

Sharfstein, J. M., \& Morphew, C. C. (2020). The urgency and challenge of opening K-12 schools in the fall of 2020. JAMA. https://doi.org/10.1001/jama.2020.10175 
Sindelar, P., Pua, D., Fisher, T., Peyton, D., Brownell, M., \& Mason-Williams, L. (2018). The demand for special education teachers in rural schools revisited: An update on progress. Rural Special Education Quarterly, 37(1), 12-20. https://doi.org/10.1177/8756870517749247

Storey, N., \& Slavin, R. (2020). The US educational response to the COVID-19 pandemic. Best Evidence in Chinese Education, 5(2), 617-633. https://doi.org/10.15354/bece.20.or027

TeachNY (2016). TeachNYAdvisory Council: Report of findings and recommendations. State University of New York. https://www.suny.edu/teachny/

Zemsky, R. (2013). Checklist for change: Making American higher education a sustainable enterprise. Rutgers University Press. https://doi.org/10.36019/9780813561356 